\title{
DIGITALCOMMONS
}

$@$ WAYNESTATE-

Wayne State University

$1-1-2005$

\section{Volunteer health professionals and emergencies: Assessing and transforming the legal environment}

James G. Hodge Jr

Johns Hopkins Bloomberg School of Public Health

Lance A. Gable

Georgetown University Law Center

Stephanie H. Cálves

Johns Hopkins Bloomberg School of Public Health

\section{Recommended Citation}

Hodge, James G., Jr. (et al.). Volunteer Health Professionals and Emergencies: Assessing and Transforming the Legal Environment. 3 Biosec. \& Bioter. 216 (2005)

Available at: https://digitalcommons.wayne.edu/lawfrp/134 


\title{
Volunteer Health Professionals and Emergencies: Assessing and Transforming the Legal Environment
}

\author{
JAMES G. HODGE, JR., LANCE A. GABLE, and STEPHANIE H. CÁLVES
}

Volunteer health professionals (VHPs) are essential in emergencies to fill surge capacity and provide needed medical expertise. While some VHPs are well-organized and trained, others arrive spontaneously at the site of a disaster. Lacking organization, training, and identification, they may actually impede emergency efforts. Complications involving medical volunteers in New York City after September 11, 2001, led Congress to authorize federal authorities to assist states and territories in developing emergency systems for the advance registration of volunteer health professionals (ESARVHP). Through advance registration, volunteers can be vetted, trained, and mobilized more effectively during emergencies. The use of VHPs, however, raises multiple legal questions: What constitutes an emergency, how is it declared, and what are the consequences? When are volunteers liable for their actions? When may volunteers who are licensed or certified in one state legally practice their profession in another state? Are volunteers entitled to compensation for harms they incur? This article examines the legal framework underlying the registration and use of volunteers during emergencies and offers recommendations for legal reform, including: (1) establish minimum standards to facilitate interjurisdictional emergency response, improve coordination, and enhance reciprocity of licensing and credentialing; (2) develop liability provisions for VHPs that balance their need to respond without significant fear of civil liability with patients' rights to legal recourse for egregious harms; and (3) provide basic levels of protections for VHPs harmed, injured, or killed while responding to emergencies.

H ISTORICAL AND MODERN RESPONSES to public health crises, natural disasters, and other emergencies that threaten individual and community health and safety have consistently featured support from volunteer health professionals (VHPs) such as physicians, nurses, public health workers, lab technicians, emergency medical responders, and psychologists. ${ }^{1-4}$ Emergency response planners count on such volunteers to fill surge capacity and provide needed medical expertise and related support functions. For example, after the terrorist attacks in New York City on September 11, 2001, more than 8,000 physicians across the country offered to respond to New York State's call for assistance. ${ }^{3,4}$

Some volunteers are organized, trained, and directed to respond through government programs (e.g., Disaster Medical Assistance Teams [DMAT], Medical Reserve Corps $[\mathrm{MRC}]$ ) and private sector efforts (e.g., American Red Cross, Orthopaedic Trauma Association Mass Casualty Teams [OTAMCT]). ${ }^{5-8}$ Others simply show up at the site of a disaster or nearby healthcare facilities. These "spontaneous volunteers" are ready to help but lack organization, identification, credentials, and, ultimately, util-

James G. Hodge, Jr., JD, LLM, is Associate Professor, Johns Hopkins Bloomberg School of Public Health, and Executive Director, Center for Law and the Public's Health, Baltimore, Maryland. Lance A. Gable, JD, MPH, is Senior Fellow, Center for Law and the Public's Health, Georgetown University Law Center, Washington, DC. Stephanie H. Cálves, JD, MPH, is a Researcher, Center for Law and the Public's Health, Johns Hopkins Bloomberg School of Public Health. 
ity. Rather than assisting in the emergency efforts, the presence of many uncoordinated volunteers can actually impede effective emergency responses. ${ }^{1,3,9}$

The experience of New York City hospitals during the September 11 tragedy exposed the difficulties that result from a proliferation of spontaneous medical volunteers. Some hospital administrators near the World Trade Center site reported that they were unable to use health professionals because they could not verify the identities or basic licensing or credentialing information for VHPs, including training, skills, competencies, and employment. Disruptions to standard telecommunications prevented hospitals from contacting other sources that could have provided verification. ${ }^{10}$

These complications led Congress to authorize the Department of Health and Human Services (DHHS) to fund and assist states and territories to develop emergency systems for the advance registration of volunteer health professionals (ESAR-VHP). ${ }^{11}$ Through advance registration at the state level, VHPs can be vetted, counseled, trained, and mobilized when needed for the benefit of individual and community health. Currently, states and territories are beginning to assess and register skilled medical professionals willing to volunteer their services during interstate and intrastate emergencies.

The establishment of interoperable, state-based registration systems will give emergency response coordinators and hospital administrators the ability to quickly identify and better utilize VHPs during emergencies and disasters, whether the responders arrive spontaneously or through a coordinated effort. These systems will also allow emergency planners to contact and mobilize needed personnel rapidly and, ultimately, to coordinate emergency responses at the regional or national levels using aggregated information. ${ }^{13}$

The Health Resources and Services Administration (HRSA), a division of DHHS, has taken the lead in facilitating the creation of advance registration systems through the ESAR-VHP program. ${ }^{12}$ Under the proposed HRSA guidelines, each state system will include readily available, verifiable, and up-to-date information regarding the volunteer's identity, licensing, credentialing, and privileging in hospitals or other healthcare facilities that might need volunteers. ${ }^{12}$

The need for VHPs during emergencies is unquestioned. However, a series of legal and regulatory questions affect their use and participation. What constitutes an "emergency" sufficient for the initiation of volunteer efforts, how is it declared, and what are the legal and practical ramifications of such declarations? When may volunteers face civil or criminal liability for their actions in response to public health emergencies? When may volunteers who are licensed or certified in one state legally practice their profession in another state? Who will compensate volunteers for the injuries or other harms they incur while responding to emergencies? These and other legal issues pervade the implementation of volunteer networks and can inhibit the full realization of volunteer services and contributions. Prospective volunteers may be reluctant to register and respond absent sufficient legal protections.

In September 2004, HRSA asked the Center for Law and the Public's Health at Georgetown and Johns Hopkins Universities to assess the legal framework governing volunteers registered through ESAR-VHP. ${ }^{13}$ In this article, we present this framework, with a focus on providing meaningful answers to key legal questions for volunteers underlying their registration and use during emergencies. We also offer recommendations to address existing legal gaps or other impediments to effective registration and use of VHPs through legal or policy reforms at the federal or state level.

\section{FRAMING THE LEGAL ENVIRONMENT FOR VOLUNTEERS IN EMERGENCIES}

Health professionals within the fields of healthcare and public health comprise an essential workforce whose efforts are necessary in any emergency where people face health or safety risks. Yet, health professionals in any particular setting (e.g., hospital, public health department, emergency care center) are a limited resource that can be quickly overwhelmed during emergencies. Additional skilled personnel will be needed to supplement the efforts of the existing healthcare workforce. Volunteer health professionals (i.e., healthcare professionals who render aid or perform health services on a temporary basis without pay or remuneration ${ }^{12}$ ) may be called on to supplement or perform the functions of government or private sector employees during emergencies. These volunteers, however, face different legal issues than their "nonvolunteer" counterparts. VHPs serve in a limited capacity, for a limited period of time, and in places or positions in which they may not normally practice. They may lack formal relationships with the entities they assist, which may affect their liability and workers' compensation coverage. The use of volunteers during emergencies raises critical legal issues related to emergency powers, licensure and credentialing, civil liability, and protection of volunteers from harms.

\section{Emergency Powers and Protections}

The organized deployment of volunteers through ESAR-VHP presupposes emergency circumstances that justify the need for additional personnel. Nearly every state has laws that authorize the governor to declare a 
general state of emergency or disaster in response to natural disasters, terrorism, or other crises. ${ }^{13}$ Some states further define and delineate procedures for the declaration of a "public health emergency," consistent with the Center's Model State Emergency Health Powers Act (MSEHPA). ${ }^{14}$ MSEHPA's conception of a "public health emergency" is more targeted than that of a "general emergency." Public health emergencies specifically involve catastrophic illnesses or health conditions that are the result of bioterrorism, emerging infectious diseases, or other serious threats to communal health. ${ }^{14,15}$

The primary intent underlying an emergency declaration is to vest emergency management, public health, or public safety authorities with additional powers and duties to effectively respond. MSEHPA, for example, allows for the suspension of ordinary state regulations, use of available resources to facilitate emergency responses, and expedited powers to manage property and protect people. ${ }^{14}$ These powers include (a) waiver of state licensing requirements for healthcare providers from other jurisdictions (as discussed below), and (b) conferment of some liability protections to providers who volunteer. ${ }^{14}$

These legal protections may be essential to the effective use of volunteer health professionals, but they come into effect only when a formal emergency declaration is made. During smaller-scale or localized emergencies that do not involve state-level concerns, a declaration of emergency may not be made even though volunteers may be needed to respond. Furthermore, VHPs could be needed to address urgent situations that are resolved quickly before an emergency is declared. Differing types of emergencies may lead to conflicting legal declarations that complicate government and private sector responses.

\section{Ensuring Surge Capacity and Qualified VHPs}

State laws and professional standards require comprehensive and methodical evaluation of a health professional's qualifications and competencies as a prerequisite to professional licensure, credentialed status, or clinical privileges. ${ }^{16,17}$ In nonemergency circumstances, these systematic requirements ensure that health professionals are well-trained and capable of treating patients in specific settings. During emergencies, however, VHPs with varying skills, training, and expertise may be needed to provide care to and coordinate treatment of patients across state or territorial boundaries. It may not be possible to systematically evaluate these volunteers in real time through standard licensing, credentialing, and privileging processes. Advance registration systems like
ESAR-VHP seek to (a) establish prequalified lists of volunteer health professionals who meet quality standards consistent with state licensure laws and professional credentialing standards, and (b) facilitate rapid deployment and evaluation of the skills, training, and capabilities of these volunteers by entities using them during an emergency. ${ }^{13}$

To facilitate effective medical responses, some states have enacted laws that waive in-state licensure requirements or grant license reciprocity for physicians, nurses, and other emergency responders during emergency situations. Minnesota, ${ }^{18}$ Connecticut, ${ }^{19}$ West Virginia, ${ }^{20}$ Illinois, ${ }^{21}$ and Ohio, ${ }^{22}$ for example, allow physicians holding licenses or permits from other states to provide care during emergencies. In addition, most states have agreed, through compacts, to provide reciprocity of licensure for physicians and nurses among state partners for emergency purposes. ${ }^{23-25}$ The Emergency Management Assistance Compact (EMAC), executed by 48 states and several territories, authorizes license reciprocity for healthcare practitioners in any member jurisdiction during "an emergency or disaster duly declared by the governor of the affected state," an organized drill, or a training exercise. ${ }^{24}$ When one state requests assistance from another through EMAC, licensed professionals responding to the request may be considered licensed or certified in the requesting state for the duration of the emergency. ${ }^{24}$ Volunteers who are not responding pursuant to the EMAC request will not receive reciprocity, unless it is provided through other legislative or regulatory provisions.

Volunteers also must satisfy credentialing and privileging requirements to provide care in hospitals and other health facilities. ${ }^{26}$ Credentialing and privileging processes involve time-consuming reviews of the practitioner's licensure, education, experience, specialty certifications, and other information that are not practical when potentially thousands of new patients need immediate care. Hospitals and other host entities must be able to quickly grant sufficient medical privileges to VHPs during emergencies.

The Joint Commission for Accreditation of Healthcare Organizations (JCAHO) mandates that hospitals and other health facilities have systems in place for granting disaster privileges to practitioners from other institutions. ${ }^{27}$ Proof of membership in a disaster response team like the MRC, DMAT, or OTAMCT, which generally require advance credentialing, may promote rapid privileging in emergencies. ${ }^{8,27}$ These standards and policies help hospitals meet surge capacity in mass casualty situations while ensuring the quality of medical treatment and services provided by VHPs. However, additional expedited licensing and credentialing provisions are needed to fa- 
cilitate the rapid professional evaluation of all potential volunteeers.

\section{Volunteer Liability for Harms to Patients}

Questions of when civil or criminal liability should stem from the actions of volunteer health professionals during emergencies raise challenging, complex issues of responsibility, causation, and justice. ${ }^{28}$ Many of these legal issues are dependent on specific facts that do not lead to simple answers. Civil liability refers to the potential responsibility that a person may have for his or her actions, or failures to act, that proximately result in injuries or losses to others. Civil liability for medical malpractice or other claims may arise from a VHP's breach or deviation from statutory, regulatory, or judicial requirements, contractual obligations, or policy statements.

Many claims are based on malpractice, which is grounded in the theory of negligence - that is, that an individual failed to adhere to a certain standard of care, resulting in an injury to another. ${ }^{13}$ The concept of standard of care is particularly relevant in emergencies when the medical capabilities of an individual practitioner or facility may be diminished due to scarcity of resources and the need to treat large numbers of patients. ${ }^{13}$ VHPs or entities who are found liable may be required to provide compensation for physical or mental injuries, property losses, or other damages. ${ }^{29}$ Criminal liability also can apply to VHPs during an emergency if their actions meet the elements of a crime (e.g., assault, battery, involuntary manslaughter).

To protect volunteer health professionals from a multitude of civil liability claims during emergencies, many states provide limited immunity or indemnification through statutory or regulatory provisions. Federal and state volunteer protection acts provide immunity to noncompensated volunteers working for government and nonprofit entities. ${ }^{30}$ These acts, however, do not grant liability protections to volunteers who provide services to for-profit entities or receive compensation for their services. Additionally, volunteer protection acts will not provide immunity from liability unless the volunteer is acting within the scope of his or her responsibilities, is properly licensed, and the "harm was not caused by willful or criminal misconduct, gross negligence, reckless misconduct, or a conscious, flagrant indifference to the rights or safety of the individual harmed by the volunteer." 30

Governmental (or sovereign) immunity provisions protect government officials and employees from civil liability for actions performed in the scope of their employment. ${ }^{31}$ Some states extend sovereign immunity protections by statutorily providing emergency volun- teers with the same rights and immunities as state employees. ${ }^{32,33}$ Similar protections may also extend to government contractors or volunteers working on the government's behalf in some states. ${ }^{34,35}$ However, volunteers providing health services outside government generally will not be entitled to sovereign immunity protections. Furthermore, these protections are not available in jurisdictions that do not have sovereign immunity or where it has been waived for healthcare practitioners. ${ }^{36,37}$

In emergencies, additional legal sources of immunity may derive from Good Samaritan statutes, emergency laws, and mutual aid compacts. Good Samaritan laws, found in every state, protect volunteers who render spontaneous care from civil liability. ${ }^{13,38,39}$ These laws typically apply to individuals who provide assistance at the scene of an emergency. Their scope of coverage varies from state to state. ${ }^{13}$ Often Good Samaritan provisions would not apply to volunteers rendering care in a healthcare facility, and in some states these provisions explicitly do not apply to health professionals.

Emergency statutes and mutual aid compacts, such as state public health emergency acts and EMAC, provide even broader (albeit varied) immunity protections for volunteers. ${ }^{13,24,40}$ Two important limitations of these provisions are (a) that their application may be limited to individuals acting in some employment or agency capacity with the state, and (b) they may only apply during a declared emergency. ${ }^{13}$

Underlying this patchwork of liability and immunity protections across states are competing, legitimate interests of patients and volunteers. People receiving healthcare and services are entitled to some compensation for their injuries and losses that occur due to negligent or wrongful acts. Concurrently, volunteer health professionals and the entities that rely on them must be able to provide health services during emergencies without being subjected to crushing burdens of debt, ethical reviews, and societal blame for inevitable mistakes that arise in triage or other rapid healthcare responses. Balancing these competing interests is vexing during a public health emergency that, by definition, involves immediate, serious, disabling threats to communal health. ${ }^{14}$ In a mass casualty or triage situation, the risk of injuries to patients may significantly increase due to resource constraints, ambiguity about the standard of care, or inadequate coordination, information, or training. ${ }^{13}$ Coupled with uncertainty about their potential liability, health professionals and facilities may be deterred from participating.

\section{Compensation for Harms to Volunteers}

In addition to their potential liability for harms to patients are concerns among volunteer health professionals 
about the predictable harms they may experience in responding to emergency events. In their regular workplaces, health professionals (like all employees) are entitled to compensation for harms through governmentadministered workers' compensation systems that provide limited benefits for work-related injuries or death, regardless of fault. ${ }^{41}$ The application of workers' compensation benefits to VHPs responding to emergencies, however, is questionable. Workers' compensation laws cover only "employees" and therefore exclude unpaid volunteers or gratuitous workers (like those registering through ESAR-VHP). ${ }^{13}$ Some states (e.g., Connecticut, ${ }^{42}$ Illinois, ${ }^{43}$ Ohio, ${ }^{44}$ and Wisconsin ${ }^{45}$ ) and local governments explicitly extend coverage to certain volunteer workers by classifying them as government employees for the duration of an emergency. EMAC provides compensation for the injury or death of members of the state emergency management forces. ${ }^{23}$

Even if workers' compensation benefits apply, determining who is actually "employing" volunteers during an emergency is challenging. Which entity is to be considered the volunteer's employer and which state's laws (or federal law) will apply if the volunteer leaves his or her regular place of employment or crosses state lines to provide services? In many jurisdictions, volunteers' existing employers are not liable for employee harms sustained while volunteering services elsewhere because the employees' actions are outside their scope of employment. ${ }^{46}$ In states that do not view VHPs as government employees, a hospital or institution in which the volunteer is temporarily working may be responsible for workers' compensation benefits, which raises concerns (and insurance premiums) for private sector hosts of volunteers.

Finally, workers' compensation benefits apply only to injuries that occur at work. ${ }^{46}$ Volunteer health professionals who suffer harms outside of their volunteer settings are simply not protected. For example, a volunteer may become infected with a disabling condition through exposure in the emergency setting, but not at the place in which he or she volunteers. Since this injury did not occur while at "work," the volunteer may be denied workers' compensation coverage.

\section{RECOMMENDATIONS FOR TRANSFORMING THE LEGAL ENVIRONMENT}

The existing legal environment underlying the registration, deployment, and use of volunteer health professionals during emergencies is complex, inconsistent, and at times ambiguous. Lacking legal clarity and assurances, volunteers can only venture cautiously into service, guessing as to their potential risks, liability, and protections. We propose several recommendations to transform the legal landscape to protect the interests of patients and VHPs while facilitating effective emergency responses.

\section{A Floor of Minimum, Consistent Legal Standards}

A floor of legal protections for volunteers is necessary to achieve consistent minimum standards between states. Under the current framework, there is great variation in the legal protections available for volunteers amongst the states. As discussed above, some states provide for liability protection and workers' compensation coverage for VHPs while others do not. The availability of legal protections may depend on (a) the specific profession or affiliation of the volunteer, (b) to whom the volunteer is providing services, and (c) whether or not there is a declared emergency. Health professionals may be reluctant to volunteer and face the risks of participating in an emergency response without clear legal protections. A minimum, consistent level of protections is necessary across all states to ensure that the risks of liability, professional admonishment, or uncompensated harm do not outweigh the altruistic instincts of potential volunteers.

The establishment of a floor of minimum legal standards for volunteers would achieve several results. By setting a baseline level of legal protections, it would guarantee that all volunteer health professionals would have a foundation of protection from risks of physical and economic harm resulting from their volunteer efforts. This guarantee encourages greater participation by VHPs, which would bolster the workforce available to meet surge capacity and improve overall emergency response efforts. Moreover, implementing a floor of legal protections will guarantee volunteers a predictable baseline level of protections that further interjurisdictional use.

Minimum standards should mandate cross-border licensure reciprocity; civil liability protections except in cases of willful, wanton, or criminal misconduct; and workers' compensation coverage for all volunteers. This proposed baseline goes beyond the current floor of protections provided by the Federal Volunteer Protection Act, which applies liability protections only to uncompensated volunteers working for government or nonprofit entities.

Several approaches may be taken to achieve a uniform floor of legal standards across the nation. Congressional action may be used to (a) delegate regulatory authority to DHHS or (b) devote new grant resources to states that include the implementation of these standards as core conditions on receipt of these funds. Promulgating federal 
standards is an attractive policy option, because they are influential and can be attached to spending allocations distributed to the states. Federal standards should not preempt state laws that grant additional legal protections to volunteers during emergencies.

A floor of legal standards can be implemented through other nonfederal options as well. For example, interstate emergency management compacts, including EMAC, could be expanded beyond their current scope. The existing structure of EMAC limits legal protections to "officers or employees of a party state." This excludes many potential volunteers. The language of EMAC could be amended to extend legal protections to all volunteers responding to an emergency, whether or not they are officers or employees of the state. Alternatively, volunteer health professionals could be deemed state employees for the duration of the emergency so that they would come within the existing EMAC definition. While amending EMAC would be politically difficult, significant advantages underlie this approach given its wide adoption among states and territories.

\section{Balanced Liability Protections}

To reduce the risk of harm to people receiving healthcare and services that may result in civil liability, laws should embrace proactive planning and training activities for volunteer health professionals and healthcare entities that may use volunteers. Laws must further balance (a) the need for volunteers to act without fear of liability during emergencies and (b) the rights of people receiving healthcare and services to some legal recourse for injuries resulting from a volunteer's care or treatment.

We recommend that medical personnel, volunteer or otherwise, should be immune from civil liability for healthcare services during declared emergencies, except when their acts involve willful, wanton, or criminal misconduct. Such a limitation is essential to ensure that people receiving healthcare and services have some form of recourse for egregious or intentional acts of medical negligence. Immunity could be provided to volunteer health professionals through explicit liability protections in state emergency health powers laws, like MSEHPA, interstate compacts covering volunteers, or the expansion of volunteer protection acts to cover all VHPs responding to emergencies.

We recognize that this recommendation largely eliminates individual causes of action for medical harms arising from noncriminal, nonegregious actions of volunteer health professionals in favor of encouraging full participation of skilled, trained VHPs during emergencies. Limitations on civil liability, however, should not prevent people who are injured through medical care during emergencies from receiving some compensation. Federal or state governments could establish alternative compensation mechanisms for exempted claims outside the tort system. These may take the form of a discrete compensation fund-modeled after Social Security Disability Insurance, workers' compensation programs, ${ }^{47,48}$ or the National Vaccine Injury Compensation Program ${ }^{49}$ - to pay claims for people injured during emergency responses without assigning blame to VHPs or their hosts or involving costly court fees. However it is organized, the goal of a victims' compensation program would be to permit people who are injured through emergency medical care to be compensated while providing volunteer health professionals with a level of liability protection to encourage them to participate in emergency response efforts. Undeniable costs of such a program are justified by principles of fairness and justice, providing affected individuals with protection from further losses resulting from negligent medical care. ${ }^{50}$

\section{Compensation for Harms to Volunteers}

Volunteers may understand the nature of risks that confront them in response to emergencies, but few may be completely able to absorb the costs of significant harms through health insurance benefits or other resources. States and territories should apply workers' compensation benefits to volunteer health professionals who are injured, disabled, or killed during emergencies. Volunteer health professionals should be defined as "employees" of the host jurisdiction during declared emergencies for the purposes of workers' compensation provided that they are volunteering in some formal capacity. Volunteers would thus be covered under the state's workers' compensation plan like any state employee. This would also eliminate concerns among the volunteer health professionals' nonemergency employers that their workers' compensation plans may be affected.

Furthermore, existing limits on workers' protections for occupational diseases should be restructured to expand coverage to volunteers who contract communicable conditions as part of their service during emergencies, regardless of whether the infection occurred in the workplace. This would have the effect of derailing inevitable postemergency debates in administrative tribunals as to the specific time and place in which a volunteer became infected. Volunteer health professionals offering their assistance during an emergency and risking their health and safety for the benefit of others should not have to defend allegations as to the specific way they contracted the condition that pervaded the workplace and community. 


\section{CONCLUSION}

Protecting patients and the public's health during emergencies requires the systematic efforts of volunteer health professionals. National, state, and territorial efforts to better organize and deploy VHPs through existing programs and state-based registries like ESAR-VHP facilitate their utility and roles in emergency circumstances. However, legal impediments may inhibit the effectiveness of registries or the full participation of some volunteer health professionals. Changes in the legal landscape after the declaration of an emergency heighten volunteer concerns about licensure, credentialing, liability, and harms. Gaps in liability protections and workers' compensation across states and territories create significant questions for volunteers responding to emergencies. We suggest transformations of the existing legal environment to clarify and change, where necessary, applicable laws that encourage volunteer health professionals to provide timely and essential care during emergencies.

\section{DISCLAIMER AND ACKNOWLEDGMENT}

The authors and the Center for Law and the Public's Health are supported at the Johns Hopkins Bloomberg School of Public Health through HRSA, Contract Number HHSH234200437001C. The authors gratefully acknowledge the intellectual contributions of their Center colleagues, Stephen P. Teret and Jon Vernick, and Center researchers, including Jessica O'Connell, Erin Fuse Brown, and Helaine Rutkow. Although HRSA participated in the review of the manuscript, the contents of this article are solely the responsibility of the authors and do not necessarily represent the official views of HRSA.

\section{REFERENCES}

1. Jackson B, Peterson DJ, Bartis J, et al. Protecting Emergency Responders: Lessons Learned from Terrorist Attacks. Santa Monica, Calif: RAND; 2002. Available at: http://www.rand.org/publications/CF/CF176/. Accessed March 26, 2005.

2. Hogan DE, Waeckerle JF, Dire DJ, Lillibridge LR. Emergency department impact of the Oklahoma City terrorist bombing. Ann Emerg Med 1999;34:160-167.

3. Cone DC, Weir SD, Bogucki S. Convergent volunteerism. Ann Emerg Med 2003;41:457-462.

4. Romano M. Medical personnel respond: physicians across the nation eager to volunteer. Mod Healthc 2001 Sep 17;31(38):24.

5. 68 FR 33144-02 (June 3, 2003).

6. Forgione T, Owens PJ, Lopes JP, Briggs SM. New hori- zons for OR nurses-Lessons learned from the World Trade Center attack. AORN J 2003 Aug;78(2):240-245.

7. Office of the Surgeon General. MRC Units. Available at: http://www.medicalreservecorps.gov/index.cfm?MRCaction $=$ MRCunit.Contact. Accessed March 27, 2005.

8. Born CT, DeLong WG. Organizing the orthopaedic trauma association casualty response team. Clin Orthop Relat Res 2004 May;(422):114-116.

9. Mason M. Infrastructure: no cure in sight. Homeland Security 2005 Mar/Apr:20-25.

10. Hoard ML, Tosatto RJ. Medical Reserve Corps: strengthening public health and improving preparedness. Disaster Manage Response 2005 Apr-Jun;3(2):48-52.

11. The Public Health Security and Bioterrorism Preparedness and Response Act of 2002, PL 107-188, 42 U.S.C.A. $\S 247 \mathrm{~d}-7 \mathrm{~b}$ (West 2005).

12. Department of Health and Human Resources, Health Resources and Services Administration. Emergency System for Advance Registration of Volunteer Health Professionals (ESAR-VHP)_Interim Technical and Policy Guidelines, Standards, and Definitions (June 2005).

13. Department of Health and Human Resources, Health Resources and Services Administration. Emergency System for Advance Registration of Volunteer Health Professionals (ESAR-VHP) — Legal and Regulatory Issues (February 2005).

14. Center for Law and the Public's Health at Georgetown and Johns Hopkins Universities. The Model State Emergency Health Powers Act. Washington, DC: Center for Law and the Public's Health; 2001. Available at: http://www.publichealthlaw.net. Accessed March 28, 2005.

15. Gostin LO, Sapsin JW, Teret SP, et al. The Model State Emergency Health Powers Act: Planning for and response to bioterrorism and naturally occurring infectious diseases. JAMA 2002;288:622-628.

16. 243 Code Mass. Reg. 3.05 (West 2005).

17. Furrow B. Health Law. St. Paul, Minn: West Group; 2000.

18. Minn. Stat. § 12.42 (1996).

19. Conn. Gen. Stat. § 20-9(b)(3) (West 2005).

20. W. Va. Code $\S 30-3-13(\mathrm{~b})(5)$ (West 2005).

21. 20 Ill. Comp. Stat. 3305/16 (West 2005).

22. Ohio Rev. Code $\$ 5502.35$ (2005).

23. National Council of State Boards of Nursing. Nurse Licensure Compact: $R N$ and LP/VN Compact. Available at: http://www.ncsbn.org/nlc/rnlpvncompact_mutual_recognition_nurse.asp Accessed October 22, 2004.

24. Emergency Management Assistance Compact, PL 104-321 (1996).

25. National Emergency Management Association. Proposed Model Intrastate Mutual Aid Legislation. Available at: http://emacweb.org/docs/NEMA\%20Proposed\%20Intrastate\%Model-Final.pdf. Accessed October 22, 2004.

26. Mo Code Regs Tit. 19, § 30-20.021 (West 2004).

27. Joint Commission for the Accreditation of Healthcare Organizations (JCAHO). Comprehensive Accreditation Manual for Hospitals: The Official Handbook. Oakbrook Terrace, Ill: Joint Commission for the Accreditation of Healthcare Organizations; 2004.

28. Apelbaum PH, Ryder ST. The third wave of federal tort re- 
form: protecting the public or pushing the constitutional envelope. Cornell J Law Public Policy 1999;8:591-659.

29. Dobbs DB. The Law of Torts. St. Paul, Minn.: West Group; 2000.

30. Federal Volunteer Protection Act of 1997, P.L.105-19 (1997); 42 USCS $\S 14501$ et. seq. (2004).

31. Vardall FJ, Wertheimer E. Torts: Cases and Problems. Charlottesville, Va: Michie Law Publishers; 1997.

32. Va. Code. Ann. \$2.2-3605(d) (West 2005).

33. Minn. Stat. Ann. § 12.22, subd. 2a (West 2005).

34. Sabatino JM. Privatization and punitives: should governmental contractors share the sovereign's immunities from exemplary damages? Ohio State Law J 1997;58:175-239.

35. Boyle v. United Technologies Corp., 487 US 500 (1988).

36. Wa. Rev. Code $\S 4.92 .090$ (West 2005).

37. N. M. Stat. Ann. § 41-4-10 (West 2005).

38. 745 Ill. Comp. Stat. 49/1 (West 2005).

39. Minn. Stat. § 604A.01 (West 2005).

40. Fox PB. Cross-border assistance in emergencies: the New England/Eastern Canadian model. New Eng J Int'l \& Comp L 2004;11:75-88.

41. Hodge JG. The intersection of federal health information privacy and state administrative law: the protection of individual health data and worker's compensation. Admin $L$ Rev 1999;51:117-144.

42. Conn. Gen. Stat. $§ \S 28-1,28-14$ (West 2005).

43. 20 Ill. Comp. Stat. $3305 / 10$ (West 2005).

44. Ohio Rev. Code Ann. $\S \S 4123.01,4122.033$ (West 2005).
45. Wis. Stat. $\S \S 102.07,166.03,166.215$ (West 2005).

46. Larson A, Larson LK. Larson's Workers' Compensation Law. Vol. 3. New York, New York: Matthew Bender; 1997.

47. Kinney ED. Administrative law approaches to medical malpractice reform. St Louis Univ Law J 2004;49:45-72.

48. Richards EP, McLean TR. Administrative compensation for medical malpractice injuries: reconciling the brave new world of patient safety and the torts system. St Louis Univ Law J 2004;49:73-104.

49. Health Resources and Services Administration. National Vaccine Injury Compensation Program Fact Sheet. Available at: http://www.hrsa.gov/osp/vicp/fact_sheet.htm. Accessed March 30, 2005.

50. Greenberger M. The 800 pound gorilla sleeps: the federal government's lackadaisical liability and compensation policies in the context of pre-event vaccine immunization programs. J Hlth Care Law \& Policy 2005;8:7-37.

Address reprint requests to: James G. Hodge, Jr., JD, LLM Associate Professor Johns Hopkins Bloomberg School of Public Health Hampton House, Room 588 624 N. Broadway Baltimore, MD 21205-1996

E-mail: jhodge@jhsph.edu 